Article

\title{
Antimicrobial Activity of Quinoline-Based Hydroxyimidazolium Hybrids
}

\author{
Daniel Insuasty ${ }^{1, * \mathbb{D}}$, Oscar Vidal ${ }^{1}$, Anthony Bernal ${ }^{1}$, Edgar Marquez ${ }^{1}\left(\mathbb{D}\right.$, Juan Guzman ${ }^{2}{ }^{\mathbb{D}}$,

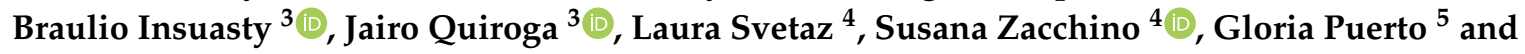 \\ Rodrigo Abonia ${ }^{3, *}$ \\ 1 Departamento de Química y Biología, Universidad del Norte, Km 5 vía Puerto Colombia, \\ Barranquilla 081007, Colombia; oorjuela@uninorte.edu.co (O.V.); awbernal@uninorte.edu.co (A.B.); \\ ebrazon@uninorte.edu.co (E.M.) \\ 2 Institute for Insect Biotechnology, Justus-Liebig-University of Giessen, 35392 Giessen, Germany; \\ Juan.D.Guzman-Vasquez@agrar.uni-giessen.de \\ 3 Research Group of Heterocyclic Compounds, Department of Chemistry, Universidad del Valle, \\ A. A. Cali 25360, Colombia; braulio.insuasty@correounivalle.edu.co (B.I.); \\ jairo.quiroga@correounivalle.edu.co (J.Q.) \\ 4 Área Farmacognosia, Facultad de Ciencias Bioquímicas y Farmacéuticas, Universidad Nacional de Rosario, \\ Suipacha 531, Rosario 2000, Argentina; laurasvetaz@hotmail.com (L.S.); szaabgil@citynet.net.ar (S.Z.) \\ 5 Laboratorio de Micobacterias, Instituto Nacional de Salud, Bogotá 111321, Colombia; gpuerto@ins.gov.co \\ * Correspondence: insuastyd@uninorte.edu.co (D.I.); rodrigo.abonia@correounivalle.edu.co (R.A.)
}

Received: 25 October 2019; Accepted: 19 November 2019; Published: 28 November 2019

check for updates

\begin{abstract}
Eight quinoline-based hydroxyimidazolium hybrids $\mathbf{7 a}-\mathbf{h}$ were prepared and evaluated in vitro against a panel of clinically important fungal and bacterial pathogens, including mycobacteria. Hybrid compounds 7c-d showed remarkable antifungal activity against Cryptococcus neoformans with a minimum inhibitory concentration (MIC) value of $15.6 \mu \mathrm{g} / \mathrm{mL}$. Against other opportunistic fungi such as Candida spp. and Aspergillus spp., these hybrids showed MIC values of $62.5 \mu \mathrm{g} / \mathrm{mL}$. Regarding their antibacterial activity, all the synthetic hybrids demonstrated little inhibition of Gram-negative bacteria (MIC $\geq 50 \mu \mathrm{g} / \mathrm{mL}$ ), however, hybrid $7 \mathbf{b}$ displayed $>50 \%$ inhibition against Klebsiella pneumoniae at $20 \mu \mathrm{g} / \mathrm{mL}$ and full inhibition at $50 \mu \mathrm{g} / \mathrm{mL}$. Moreover, this hybrid was shown to be a potent anti-staphylococcal molecule, with a MIC value of $2 \mu \mathrm{g} / \mathrm{mL}(5 \mu \mathrm{M})$. In addition, hybrid 7h also demonstrated inhibition of Staphylococcus aureus at $20 \mu \mathrm{g} / \mathrm{mL}(47 \mu \mathrm{M})$. Hybrids $7 \mathbf{a}$ and $7 \mathbf{b}$ were the most potent against Mycobacterium tuberculosis H37Rv with MIC values of 20 and $10 \mu \mathrm{g} / \mathrm{mL}$ (46 and $24 \mu \mathrm{M})$, respectively. The $7 \mathbf{b}$ hybrid demonstrated high selectivity in killing S. aureus and M. tuberculosis H37Rv in comparison with mammalian cells (SI >20), and thus it can be considered a hit molecule for mechanism of action studies and the exploration of related chemical space.
\end{abstract}

Keywords: quinoline-based hydroxyimidazolium hybrids; antimicrobial activity; antifungal activity; tuberculosis; cytotoxicity

\section{Introduction}

The intensive use of antibacterial and antifungal drugs has led to an increase in difficult-to-eradicate infections [1]. In recent years, the trend in reducing infectious disease mortality has been threatened by the emergence of strains of bacteria that are no longer susceptible to the currently available antimicrobial agents such as the Gram-negative Acinetobacter baumannii, Pseudomonas aeruginosa, or the Gram-positive Enterococcus faecium, or Staphylococcus aureus added to the multi- and extensivelydrug-resistant Mycobacterium tuberculosis. Regarding fungi, they are also a source of concern in antifungal chemotherapy because many fungi can be opportunistic pathogens seriously affecting 
immunocompromised patients, and some of them, such as Candida albicans, Cryptococcus neoformans, and Aspergillus spp. can cause complicated systemic infections that are associated with high mortality rates [2].

With the rise of the difficult-to-eradicate infectious diseases, the need for new antimicrobial agents is urgently needed. A promising strategy for the development of new antimicrobial drugs is the synthesis of molecular hybrids containing two or more covalently joined antimicrobial pharmacophores within a single molecule [3-5].

Quinoline moiety is historically important because it is present in the Cinchona alkaloids quinine and quinidine, which were the first useful treatment for malaria. Based on the activity of these natural products, several quinoline-based molecules have shown to be effective inhibitors of essential proteins from microbial pathogens [6]. For that, synthetic antimalarials have been developed, and some of them, such as amodiaquine, chloroquine (I in Figure 1), mefloquine (II in Figure 1), and piperaquine are still used clinically today, as they are recommended by the WHO [7]. One of the by-products of the synthesis of chloroquine was identified as an active antibacterial principle in 1960, and further research led to the discovery of nalidixic acid in 1962 and later to the fluoroquinolone class of antibacterials [8]. Their clinical importance is evident, as these were highly active against most Enterobacteriaceae, which includes common pathogens such as Escherichia coli, Salmonella spp., Yersinia pestis, and others, and in addition these molecules are unique to targeting bacterial DNA topoisomerases [9]. Moreover, other quinoline-containing compounds have been developed as antibacterial drugs, and one remarkable example is bedaquiline (III in Figure 1). This diarylquinoline derivative is a first-in-class anti-tuberculosis drug, acting by inhibition of mycobacterial ATP synthase and approved to treat multiple-drug resistant tuberculosis [10].

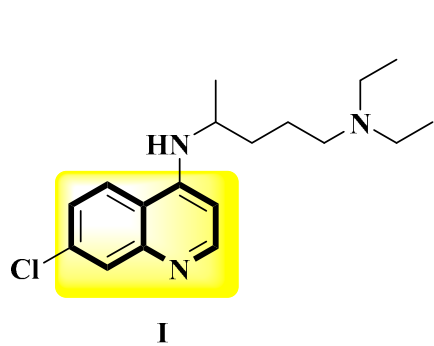

Chloroquine

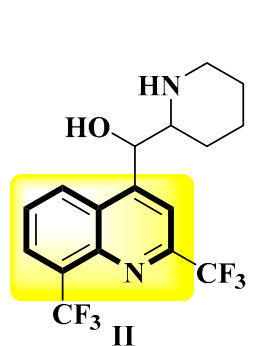

Mefloquine

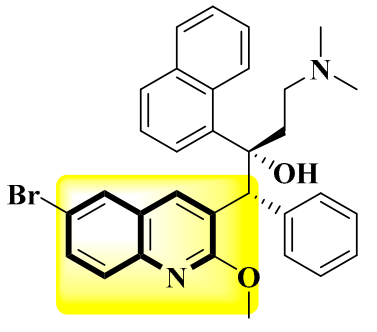

III

Bedaquiline

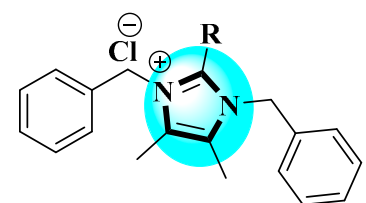

IV

lepidiline A R: H lepidiline B R: $\mathrm{CH}_{3}$

Figure 1. Some examples of biologically important quinoline- and imidazolium-derivatives.

Although quaternary ammonium salts such as benzalkonium and cetylpyridinium chlorides salts have been used for a long time as antiseptics in a variety of pharmaceutical and cosmetic products [11,12], the imidazolium salts are not used as antiseptics, nor are they constitutive fragment of any drug thus far. In contrast, the imidazole ring is a common moiety in antifungal chemotherapeutic agents such as clotrimazole, ketoconazole, and miconazole [13-15]. Interestingly, the imidazolium moiety is present in the lepidilines (IV in Figure 1), which are in fact antitumoral natural products from the Neotropical plant Lepidium meyenii [16]. Synthetic natural products analogs showed potent antimicrobial [17] and antitumoral activities [18,19]. The interesting biological properties of imidazolium salts may be explained by the possibility of not only engaging in ion-dipole and hydrogen bond interactions but also to participate in acid-base reactions and to coordinate metal atoms. This versatility opens the door to tuning their selectivity by covalent linking with appropriate steric and electrostatic scaffolds directed to particular biochemical targets.

In this work, eight quinoline-based hydroxyimidazolium hybrids $\mathbf{7 a - h}$ were prepared and evaluated against a panel of clinically important fungal and bacterial pathogens, including Mycobacterium tuberculosis H37Rv. 


\section{Results and Discussion}

\subsection{Chemistry}

The synthesis of the quinoline-based hydroxyimidazolium hybrids 7 was carried out by following our previously reported methodology [20]. Briefly, the non-commercial 3-formyl-2-oxo-quinoline and 3-formyl-2-alkoxy-quinoline precursors $\mathbf{5 a - h}$ were synthesized by a Meth-Cohn reaction [21], followed by acid hydrolysis and alkylation (Figure 2). Subsequently, the aldehydes $\mathbf{5 a - h}$ were subjected to reaction with 3-butyl-1-methylimidazolium chloride ([Bmim]Cl) 6 in the presence of AcONa and ACN as a solvent, under ultrasound irradiation at $80{ }^{\circ} \mathrm{C}$ during $1-7 \mathrm{~h}$. This straightforward procedure afforded the corresponding quinoline-based hydroxyimidazolium hybrids $7 \mathbf{a}-\mathbf{h}$ in $60-91 \%$ yield. Structures of hybrids 7 were confirmed by ${ }^{1} \mathrm{H}$ NMR (see Figure S1 in Supplementary Materials).

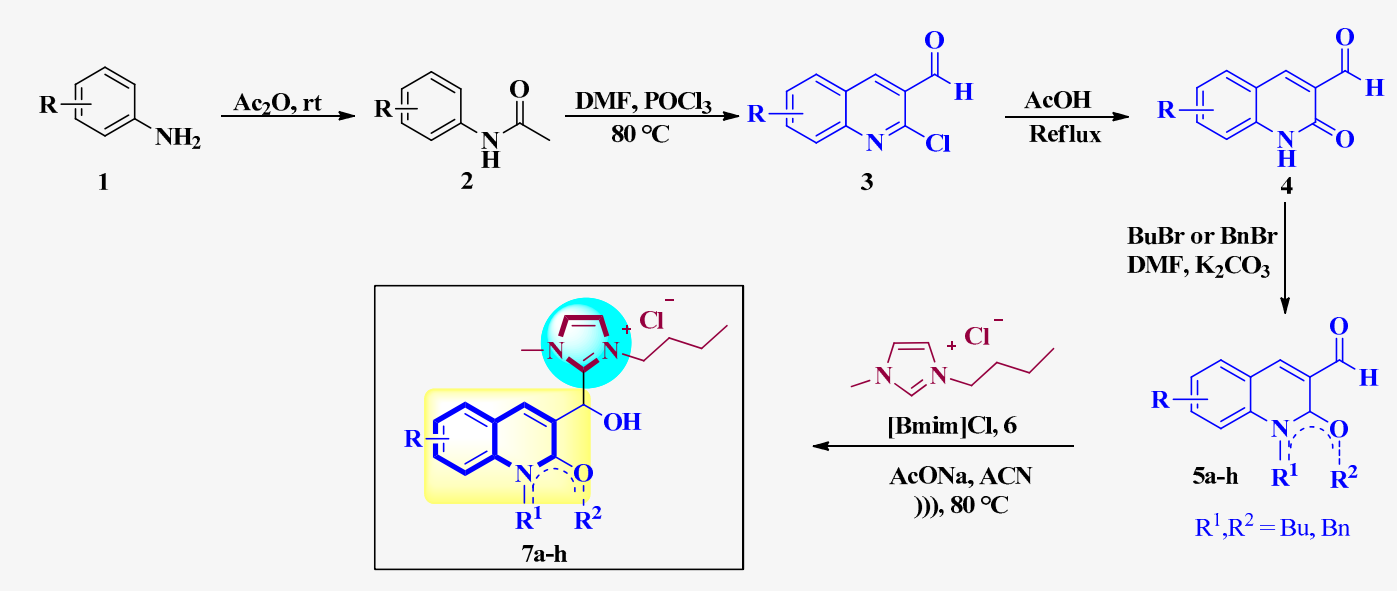<smiles>CCCC[n+]1ccn(C)c1C(O)c1cc2cc(OC)ccc2nc1OCCC</smiles>

$7 \mathbf{a}$<smiles></smiles>

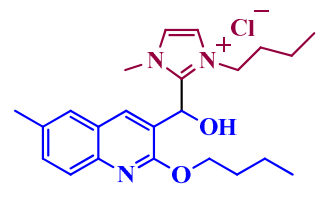

$7 \mathbf{b}$

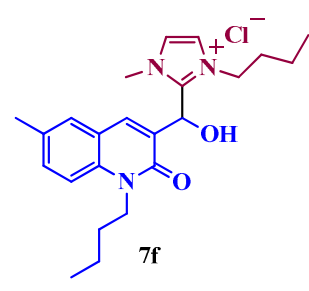<smiles>CCCCOc1nc2c(C)cccc2cc1C(O)c1n(C)cc[n+]1CCCC</smiles>

$7 \mathbf{c}$<smiles></smiles>

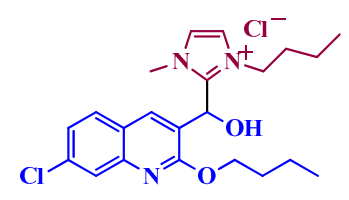

$7 \mathbf{d}$<smiles>CCCC[n+]1ccn(C)c1C(O)c1cc2ccccc2n(Cc2ccccc2)c1=O</smiles>

Figure 2. Synthesis of quinoline-based hydroxyimidazolium hybrids $\mathbf{7 a - h}$.

\subsection{Antifungal Activity}

Hybrids $\mathbf{7 a}-\mathbf{h}$ were tested in vitro for antifungal activity against the most common causes of invasive fungal diseases Candida albicans and Cryptococcus neoformans and the molds Aspergillus niger, Aspergillus fumigatus, and Aspergillus flavus. The minimum inhibitory concentration (MIC) of all hybrids was determined with the clinical and laboratory standards institute (CLSI) microbroth dilution methods M27-A3 and M38-A2 [22,23]. Hybrids with MICs $>250 \mu \mathrm{g} / \mathrm{mL}$ were considered inactive; in the range of 250 to $62.5 \mu \mathrm{g} / \mathrm{mL}$, with moderate or low activity, and hybrids with MICs $\leq 31.25 \mu \mathrm{g} / \mathrm{mL}$ were considered high activity. 
Results in Table 1 clearly show that C. neoformans were the most susceptible sp., with all hybrids showing some degree of antifungal activity with MIC values between 15.6 and $250 \mu \mathrm{g} / \mathrm{mL}$. Instead, MIC values of $7 \mathbf{a}-\mathbf{h}$ against C. albicans were in the range of 62.5 to $(>250 \mu \mathrm{g} / \mathrm{mL})$ with two hybrids (7e and $7 \mathrm{~h}$ ) showing to be inactive (MIC $>250 \mu \mathrm{g} / \mathrm{mL}$ ). Regarding Aspergillus spp., they were the less sensitive spp, since 5 hybrids (7a, $7 \mathbf{b}, 7 \mathbf{e}-\mathbf{g}$ ) (of the 8 hybrids tested) were inactive.

Table 1. Minimum inhibitory concentration (MIC in $\mu \mathrm{g} / \mathrm{mL}$ ) of hybrids $\mathbf{7 a}-\mathbf{h}$.

\begin{tabular}{|c|c|c|c|c|c|c|c|c|c|c|}
\hline Structure & Hybrid & $\mathbf{R}_{1}$ & $\mathbf{R}_{2}$ & $\mathbf{R}_{3}$ & $\mathbf{R}_{4}$ & $C a$ & $C n$ & $A f u$ & $A f l$ & $A n i$ \\
\hline & $7 a$ & $\mathrm{OMe}$ & $\mathrm{H}$ & $\mathrm{H}$ & - & 125 & 62.5 & $\mathrm{i}$ & $\mathrm{i}$ & $\mathrm{i}$ \\
\hline & $7 \mathrm{~b}$ & $\mathrm{Me}$ & $\mathrm{H}$ & $\mathrm{H}$ & - & 62.5 & 62.5 & $\mathrm{i}$ & $\mathrm{i}$ & $\mathrm{i}$ \\
\hline & $7 \mathrm{c}$ & $\mathrm{H}$ & $\mathrm{H}$ & $\mathrm{Me}$ & - & 62.5 & 15.6 & 62.5 & 62.5 & 62.5 \\
\hline $\mathbf{R}_{3}$ & $7 d$ & $\mathrm{H}$ & $\mathrm{Cl}$ & $\mathrm{H}$ & - & 62.5 & 15.6 & 62.5 & 62.5 & 62.5 \\
\hline & $7 e$ & $\mathrm{OMe}$ & $\mathrm{H}$ & $\mathrm{H}$ & $\mathrm{Bu}$ & $\mathrm{i}$ & 250 & $\mathrm{i}$ & $\mathrm{i}$ & $\mathrm{i}$ \\
\hline & $7 \mathrm{f}$ & $\mathrm{Me}$ & $\mathrm{H}$ & $\mathrm{H}$ & $\mathrm{Bu}$ & 250 & 125 & $\mathrm{i}$ & $\mathrm{i}$ & $\mathrm{i}$ \\
\hline & $7 g$ & $\mathrm{H}$ & $\mathrm{Cl}$ & $\mathrm{H}$ & $\mathrm{Bu}$ & 250 & 62.5 & $\mathrm{i}$ & $\mathrm{i}$ & $\mathrm{i}$ \\
\hline $\begin{array}{ll}R_{3} & R_{4}\end{array}$ & $7 \mathrm{~h}$ & $\mathrm{H}$ & $\mathrm{H}$ & $\mathrm{H}$ & Bn & $\mathrm{i}$ & 250 & 250 & 250 & 250 \\
\hline & AmpB & & & & & 0.78 & 0.25 & 0.50 & 0.50 & 0.50 \\
\hline
\end{tabular}

Antifungal activity was determined with the microbroth dilution assay following the clinical laboratory standards institute (CLSI) guidelines; inactive (i) = MIC $>250 \mu \mathrm{g} / \mathrm{mL}$; Ca: Candida albicans ATCC10231, Cn: Cryptococcus neoformans ATCC32264, An: Aspergillus niger ATCC9029, Afl: Aspergillus flavus ATCC9170, Afu: Aspergillus fumigatus ATCC26934. AmpB: Amphotericin B; Bu = Butyl; Bn: benzyl.

In order to have a deeper look at the antifungal behavior of hybrids 7 against $C$. neoformans, the percentages of inhibition of $C$. neoformans for each hybrid $7 \mathbf{a}-\mathbf{h}$ at concentrations from 250 to $3.90 \mu \mathrm{g} / \mathrm{mL}$ (obtained by two-fold dilutions) were determined. Results are recorded in Table 2 and represented in Figure 3, where the differences in the activity of the 7 hybrids 7 against $C$. neoformans can be clearly observed.

Table 2. Percentages of inhibition of C. neoformans ATCC 32264 by hybrids $7 \mathbf{a}-\mathbf{h}$.

\begin{tabular}{|c|c|c|c|c|c|c|c|c|}
\hline \multirow{2}{*}{ Comp. } & \multicolumn{7}{|c|}{ Concentration in $\mu \mathrm{g} / \mathrm{mL}$} & \multirow{2}{*}{$\begin{array}{l}\text { MIC in } \\
\mu \mathrm{g} / \mathrm{mL}\end{array}$} \\
\hline & 250 & 125 & 62.50 & 31.25 & 15.62 & 7.81 & 3.90 & \\
\hline $7 a$ & 100 & 100 & 100 & $43.6 \pm 3.86$ & $18.60 \pm 8.59$ & $4.72 \pm 1.39$ & 0 & 62.5 \\
\hline $7 b$ & 100 & 100 & 100 & $92.58 \pm 4.81$ & $67.84 \pm 5.66$ & $57.14 \pm 4.93$ & $12.54 \pm 0.36$ & 31.25 \\
\hline $7 \mathrm{c}$ & 100 & 100 & 100 & 100 & 100 & $53.45 \pm 4.42$ & $48.41 \pm 4.63$ & 15.62 \\
\hline $7 d$ & 100 & 100 & 100 & 100 & 100 & $67.59 \pm 9.19$ & 0 & 15.62 \\
\hline $7 e$ & 100 & $62.46 \pm 0.30$ & $41.46 \pm 0.58$ & $38.79 \pm 3.79$ & $29.92 \pm 6.13$ & $17.19 \pm 0.91$ & $8.23 \pm 3.18$ & 250 \\
\hline $7 \mathrm{f}$ & 100 & 100 & $49.28 \pm 3.20$ & $24.91 \pm 0.15$ & $19.01 \pm 3.40$ & $9.34 \pm 2.90$ & 0 & 62.5 \\
\hline $7 \mathrm{~g}$ & 100 & $94.15 \pm 4.15$ & $90.90 \pm 7.60$ & $50.44 \pm 2.09$ & $30.94 \pm 5.61$ & $25.50 \pm 5.35$ & 0 & 250 \\
\hline $7 \mathrm{~h}$ & 100 & $76.77 \pm 1.91$ & $48.99 \pm 3.00$ & $46.84 \pm 5.32$ & $35.32 \pm 2.02$ & $22.76 \pm 2.87$ & $2.52 \pm 0.56$ & 250 \\
\hline AmpB & 100 & 100 & 100 & 100 & 100 & 100 & 100 & 0.25 \\
\hline
\end{tabular}
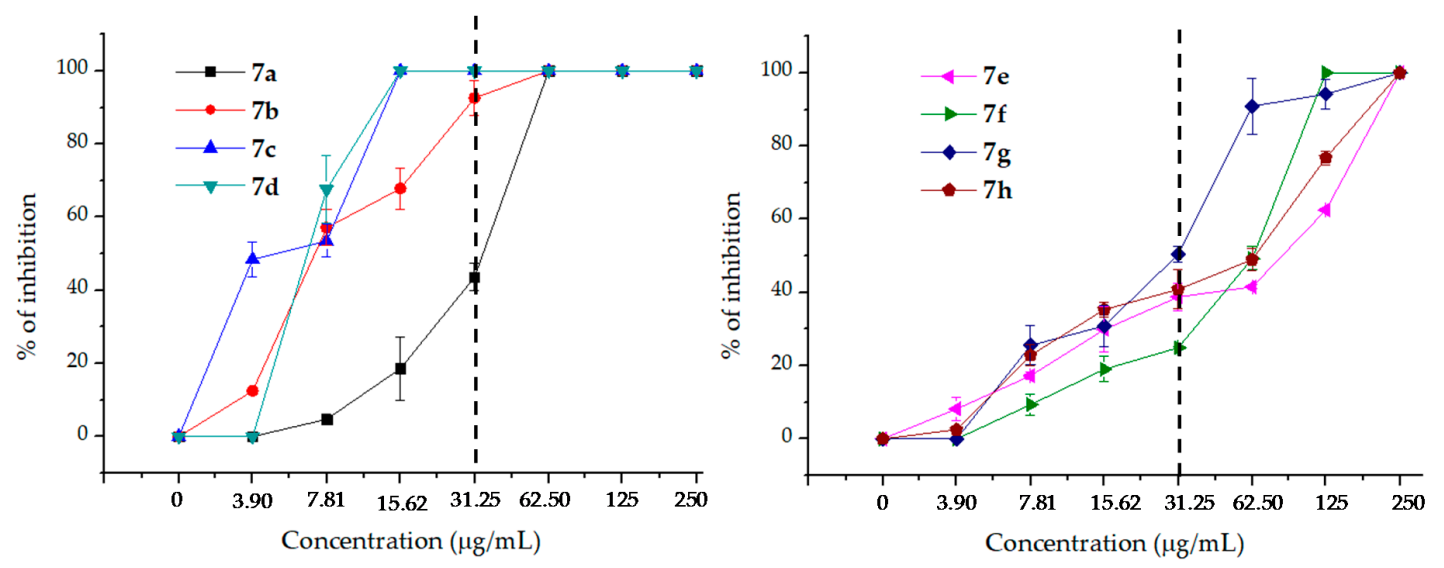

Figure 3. Dose-response curves of hybrids 7a-d (left) y 7e-h (right) against C. neoformans ATCC 32264. 
Table 2 shows that the hybrids derived from 2-alkoxy-quinolines (7a-d) were more potent than those from 2-oxo-quinolines (7e-h), and this can clearly be seen in Figure 3.

The dotted lines show the percentages of inhibition of the hybrids at $31.25 \mu \mathrm{g} / \mathrm{mL}$ and is useful to clearly observe the behavior of the hybrids at lower concentrations that are considered highly active. In Figure 3, it can be corroborated that $7 \mathbf{a}-\mathbf{d}$ possess higher anti-cryptococcal activity than $7 \mathbf{e}-\mathbf{h}$ since the inhibition percentages of $\mathbf{7 a - d}$ at concentrations $\leq 31.25 \mu \mathrm{g} / \mathrm{mL}$ are clearly higher than those of $\mathbf{7 e - h}$.

From the above results, some preliminary structure-activity relationships can be drawn: (i) The methoxy group in position C-6 (hybrid 7a), induced a relative lower activity than the methyl group in the same position (hybrid $\mathbf{7 b}$ ), as shown in Tables 1 and 2. (ii) The methyl group in position C-8 of the hybrid 7c seemed to confer a significant increase in antifungal potency compared with the methyl group in position C-6 of hybrid 7b. (iii) Hybrids 7c and 7d showed the same MIC (15.62 $\mu \mathrm{g} / \mathrm{mL})$ values, although $7 \mathrm{c}$ seemed to be more potent than $\mathbf{7 d}$, as evidenced by the much stronger inhibition displayed by $7 \mathrm{c}$ at $3.9 \mu \mathrm{g} / \mathrm{mL}$, (see Table 2). This finding could suggest that either the chlorine atom at position C-7 in $\mathbf{7 d}$ decreased the activity or the methyl group in position C-8 (hybrid $7 \mathbf{c}$ ) increased the antifungal effect, or that both played a significant role in the activity. (iv) The same detrimental trend by the chlorine atom in position C-7 on the antifungal activity was also observed when comparing the $N$-butylated hybrids 7f $(6-\mathrm{Me})(\mathrm{MIC}=125 \mathrm{mg} / \mathrm{L})$ with $7 \mathrm{~g}(7-\mathrm{Cl})(\mathrm{MIC}=250 \mathrm{mg} / \mathrm{L}$. (v) Nevertheless, the methyl group in position C-6 (hybrid $7 \mathbf{b}$ ) induced a lower activity even than the chlorine atom at position C-7 in 7d, affording MIC values of 15.62 and 31.25, respectively, Table 2. (vi) Additionally, comparison of the activity of the O-butylated hybrid $7 \mathbf{b}(\mathrm{MIC}=31.25)$ with the $N$-butylated hybrid $7 \mathrm{f}(\mathrm{MIC}=62.5)$, both possessing a 6-Me substituent, indicated that not only this substituent and its position contributed to the activity of the synthesized hybrids 7 .

\subsection{Antibacterial Activity}

The hybrids 7a-h were tested against two Gram-negative microorganisms; Escherichia coli and Klebsiella pneumoniae, a Gram-positive bacteria, Staphylococcus aureus, and two acid-fast slow-growing mycobacteria Mycobacterium tuberculosis H37Rv and Mycobacterium bovis BCG. Results for each hybrid were expressed as minimum inhibitory concentration values (MICs, $\mu \mathrm{g} / \mathrm{mL}$ and $\mu \mathrm{M}$ ), as shown in Table 3. Chloramphenicol was used as a positive control for E. coli, K. pneumoniae, and S. aureus, and isoniazid for mycobacteria. All the synthetic hybrids showed little activity against the Gram-negative organisms with MIC values $\geq 50 \mu \mathrm{g} / \mathrm{mL}$. Against $K$. pneumoniae, hybrids $7 \mathbf{a}$ and $7 \mathbf{b}$ showed to be the most potent, as evidenced by their moderate growth inhibition at high concentration (Figure 4). The hybrid $\mathbf{7 b}$ demonstrated a potent anti-staphylococcal activity with a MIC value of $2 \mu \mathrm{g} / \mathrm{mL}(5 \mu \mathrm{M})$. The hybrid $\mathbf{7 h}$ also demonstrated a significant inhibition against $S$. aureus with a MIC value of $20 \mu \mathrm{g} / \mathrm{mL}$ $(47 \mu \mathrm{M})$ and should also be considered as a hit molecule for exploring related chemical space. Hybrids $7 \mathbf{a}$ and $\mathbf{7 b}$ showed significant inhibition against $M$. tuberculosis H37Rv with MIC values of 20 and $10 \mu \mathrm{g} / \mathrm{mL}$ (46 and $24 \mu \mathrm{M}$ ), respectively. The remaining hybrids $\mathbf{7 d}, \mathbf{7 e}$, and $\mathbf{7 h}$ displayed moderate growth inhibition against the virulent H37Rv strain with MIC values of $50 \mu \mathrm{g} / \mathrm{mL}(-115 \mu \mathrm{M})$. A similar trend of activity was found against $M$. bovis BCG, confirming their antimycobacterial effect. 
Table 3. Minimum inhibitory concentration values against E. coli, K. pneumoniae, S. aureus, M. tuberculosis H37Rv and M. bovis BCG for the synthetic hybrids 7a-h.

\begin{tabular}{|c|c|c|c|c|c|}
\hline \multirow{2}{*}{ Hybrid } & \multicolumn{5}{|c|}{ MICs in $\mu \mathrm{g} / \mathrm{mL}(\mu \mathrm{M})$} \\
\hline & E. coli & K. pneumoniae & S. aureus & M. bovis BCG & M. tuberculosis H37Rv \\
\hline $7 a$ & $100(231)$ & $100(231)$ & $100(231)$ & $50(115)$ & $20(46)$ \\
\hline $7 \mathbf{b}$ & $200(480)$ & $50(120)$ & $2(5)$ & $50(120)$ & $10(24)$ \\
\hline $7 \mathrm{c}$ & $200(480)$ & $200(480)$ & $100(240)$ & $200(480)$ & $200(480)$ \\
\hline $7 d$ & $100(229)$ & $200(457)$ & $100(229)$ & $50(114)$ & $50(114)$ \\
\hline $7 e$ & $200(462)$ & $100(231)$ & $100(231)$ & $50(115)$ & $50(115)$ \\
\hline $7 f$ & $200(478)$ & $200(478)$ & $200(478)$ & $200(478)$ & $100(239)$ \\
\hline $7 \mathrm{~g}$ & $200(228)$ & $100(114)$ & $100(114)$ & $100(228)$ & $100(228)$ \\
\hline $7 \mathrm{~h}$ & $100(228)$ & $100(228)$ & $20(47)$ & $50(114)$ & $50(114)$ \\
\hline chloramphenicol & $20(62)$ & $20(62)$ & $20(62)$ & nd & nd \\
\hline isoniazid & nd & nd & nd & $0.05(0.36)$ & $0.05(0.36)$ \\
\hline
\end{tabular}
nd $=$ not determined.

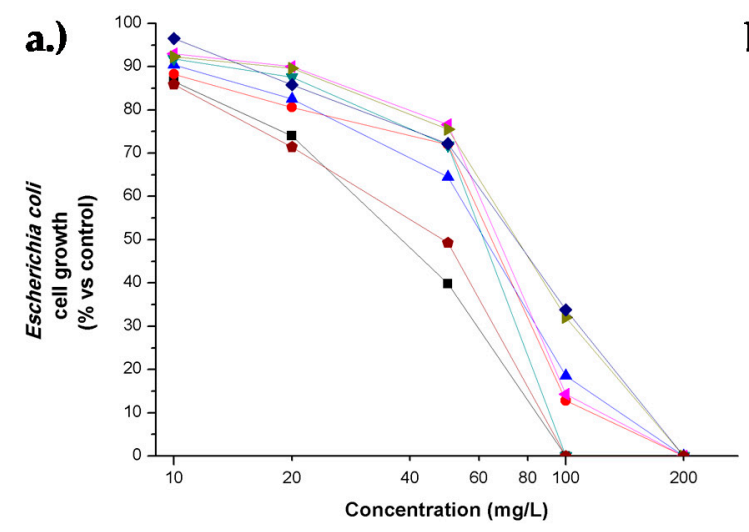

c.)

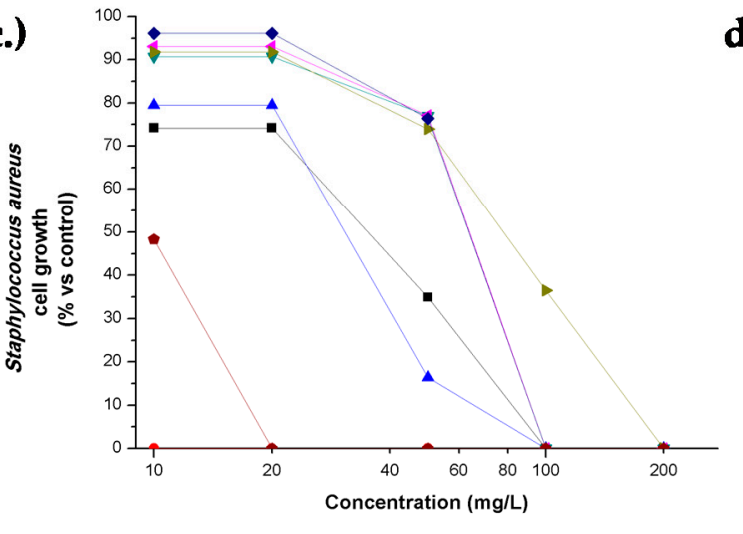

b.)

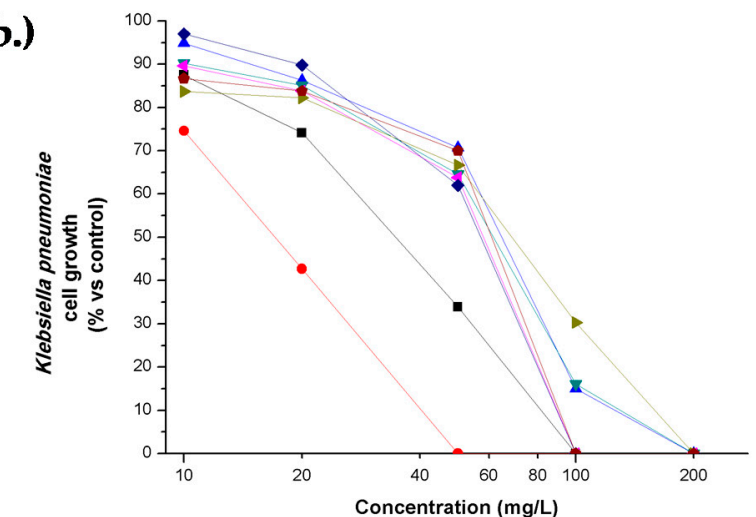

d.)

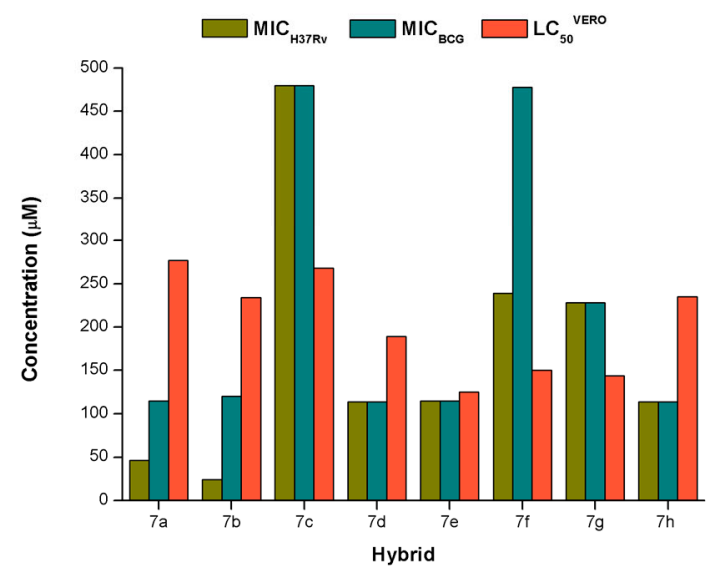

Figure 4. Antibacterial activity of hybrids 7a-h. Comparative dose-response curves of hybrids 7a-h against (a) E. coli, (b) K. pneumoniae, and (c) S. aureus. (d) Comparison of the concentrations required for anti-mycobacterial and cytotoxic effects against M. tuberculosis H37Rv, M. bovis BCG, and (Verda Reno) VERO cell line.

The anti-mycobacterial response of the hybrids towards the non-virulent $M$. bovis BCG and the virulent $M$. tuberculosis H37Rv was compared (Table 3). A correlation in MIC between the two organisms was found to be 0.8 for this dataset. Substitution at C-6 as in $7 \mathbf{a}$ and $7 \mathbf{b}$ seemed to be essential for increasing the anti-mycobacterial effect, whereas benzyl substitution on the nitrogen atom, as in $\mathbf{7 h}$, seemed to promote anti-staphylococcal activity. A number of antimicrobial quinolone hybrids have been published in recent literature [24,25], and although some of these hybrids were 
active against Gram-negative bacteria, only the hybrids with chloroquine and triclosan [26], showed inhibition of $S$. aureus at concentrations comparable (MIC-2 mg/L) to our best results. Against Mycobacterium tuberculosis, the hybrids of quinolone and pyrazole displayed inhibitory values (MIC $12.5-50 \mathrm{mg} / \mathrm{L}$ ) similar to our results [27]. However, evidently other quinoline derivatives are more potent antimycobacterial agents [28] and were developed, for instance, as the currently approved drug bedaquiline.

In summary, the hybrid $\mathbf{7 b}$ represents a promising molecule showing significant antibacterial effect against $S$. aureus $(5 \mu \mathrm{M})$ and $M$. tuberculosis H37R $(24 \mu \mathrm{M})$, for which the study of its mechanism of action should be undertaken to assess its potential development as an anti-infective agent. In this direction, some previous reports indicated that quinoline hybrids, along with other nitrogen-containing heterocycles have shown to bind to heme and hemozoin unities, but also DNA, acetylcholinesterase, or to affect prostaglandin production [29-33]. The hits discovered in this study open the door for the exploration of a focused library of compounds and to deepen the study of their antimicrobial mechanism of action.

\subsection{Cytotoxicity and Selective Index}

The cytotoxic activity of the hybrids 7a-h was evaluated by an MTT (3-(4,5-dimethyl-2-thiazolyl)2,5-diphenyl-2H-tetrazolium bromide) assay on VERO Cells (ATCC ${ }^{\circledR}$ CCL-81 ${ }^{\mathrm{TM}}$ ) with peroxide as a positive control and dimethyl sulfoxide (DMSO) as a negative control. VERO cell line growth was expressed as half-lethal concentration $\left(\mathrm{LC}_{50}\right)$ values and are summarized in Table 4.

Table 4. Cytotoxic activity $\left(\mathrm{LC}_{50}\right)$ in VERO cells and selectivity index (SI) of the active synthetic hybrids

7a-h, for E. coli, K. pneumoniae, S. aureus, M. tuberculosis H37Rv and M. bovis BCG.

\begin{tabular}{|c|c|c|c|c|c|c|}
\hline \multirow{2}{*}{ Hybrid } & \multicolumn{6}{|c|}{ Selectivity Index (SI) (SI = $\left.\mathrm{LC}_{50} / \mathrm{MIC}\right)$} \\
\hline & $\begin{array}{l}\text { Cytotoxicity } \\
L C_{50} \text {-Vero cells }\end{array}$ & E. coli & K. pneumoniae & S. aureus & $\begin{array}{l}\text { M. bovis } \\
\text { BCG }\end{array}$ & $\begin{array}{c}\text { M. tuberculosis } \\
\text { H37Rv }\end{array}$ \\
\hline $7 \mathbf{a}$ & $277 \pm 14.6$ & 2.77 & 2.77 & 2.77 & 5.54 & 13.9 \\
\hline $7 \mathbf{b}$ & $234 \pm 4$ & 1.17 & 4.68 & 117 & 4.68 & 23.4 \\
\hline $7 \mathrm{c}$ & $268 \pm 5.69$ & 1.34 & 1.34 & 2.68 & 1.34 & 1.34 \\
\hline $7 \mathrm{~d}$ & $189 \pm 14.5$ & 1.89 & 0.94 & 1.89 & 3.78 & 3.78 \\
\hline $7 e$ & $125 \pm 22$ & 0.62 & 1.25 & 1.25 & 2.5 & 2.50 \\
\hline $7 f$ & $150 \pm 12.2$ & 0.75 & 0.75 & 0.75 & 0.75 & 1.50 \\
\hline $7 g$ & $144 \pm 8.9$ & 1.44 & 1.44 & 1.44 & 1.44 & 1.44 \\
\hline $7 \mathrm{~h}$ & $235 \pm 6.5$ & 2.35 & 2.35 & 11.8 & 4.70 & 4.70 \\
\hline
\end{tabular}

Examination of cytotoxic activity of the hybrids $\mathbf{7 a - h}$ on the green monkey VERO cell line showed, in general, a low effect with $\mathrm{LC}_{50}$ values higher than $125 \mu \mathrm{M}$ (Table 4). The 2-alkoxy-quinolines (7a-d) showed to be slightly less cytotoxic $\left(\mathrm{LC}_{50} \sim 189-277 \mu \mathrm{M}\right)$ than the 2-oxo-quinolines $(7 \mathbf{e}-\mathbf{h})\left(\mathrm{LC}_{50} \sim\right.$ 125-235 $\mu \mathrm{M}$ ). The selectivity index (SI) was calculated as the ratio between $\mathrm{LC}_{50}$ on VERO cells and MIC against bacteria. As the cytotoxic concentrations were relatively similar, the hybrids with lower MIC values such as $\mathbf{7 a}, \mathbf{7 b}$, and $\mathbf{7 h}$, showed higher selectivity. Specifically, the hybrid $\mathbf{7 b}$ showed high SI values of 117 and 23.4 for S. aureus and M. tuberculosis H37Rv. The SI is an indirect measure of the therapeutic window, and it can serve as a predictor of safety during in vivo trials for a given bacterial infection.

\section{Materials and Methods}

\subsection{Antifungal Activity}

\subsubsection{Microorganisms and Media}

For the antifungal evaluation, standardized strains from the American type culture collection (ATCC, Manassas, VA, USA), and CEREMIC (CCC, Centro de Referencia en Micología, Facultad 
de Ciencias Bioquímicas y Farmacéuticas, Rosario, Argentina) were used: C. albicans ATCC 10231, C. neoformans ATCC 32264, A. flavus ATCC 9170, A. fumigatus ATTC 26934, A. niger ATCC 9029. Strains were grown on Sabouraud-chloramphenicol agar slants for $48 \mathrm{~h}$ at $30{ }^{\circ} \mathrm{C}$, maintained on slopes of Sabouraud-dextrose agar (SDA, Oxoid, Cambridge, UK) and sub-cultured every 15 days to prevent pleomorphic transformations. Inocula were obtained according to reported procedures [22,23] and adjusted to $1-5 \times 10^{3}$ cells with colony-forming units $(\mathrm{CFU}) / \mathrm{mL}$.

\subsubsection{Antifungal Susceptibility Testing}

Minimum inhibitory concentration (MIC) of each hybrid was determined by using broth microdilution techniques according to the guidelines of the Clinical and Laboratory Standards Institute for yeasts (M27-A3) [22] and for filamentous fungi (M38 A2) [23]. MIC values were determined in RPMI-1640 (Sigma-Aldrich, St Louis, MO, USA) buffered to pH 7.0 with MOPS (3-(N-morpholino)propanesulfonic acid). Microtiter trays were incubated at $35{ }^{\circ} \mathrm{C}$ for yeasts and Aspergillus spp. MICs were visually recorded at $48 \mathrm{~h}$ for yeasts, and at a time according to the control fungus growth, for Aspergillus spp. For the assay, stock solutions of the hybrids were 2-fold diluted with RPMI-1640 from 250 to $3.90 \mu \mathrm{g} / \mathrm{mL}$ (final volume $=100 \mu \mathrm{L}$ ) and a final DMSO concentration $\leq 1 \%$. A volume of $100 \mu \mathrm{L}$ of inoculum suspension was added to each well, with the exception of the sterility control where sterile water was added to the well instead. Amphotericin B (Sigma-Aldrich, St Louis, MO, USA) was used as positive control. Endpoints were defined as the lowest concentration of drug resulting in total inhibition (MIC) of visual growth compared to the growth in the control wells containing no antifungal drug.

\subsubsection{Fungal Growth Inhibition Percentage Determination}

This determination was performed with the yeast C. neoformans ATCC 32264. For the assay, compound test wells (CTWs) were prepared with stock solutions of each hybrid in DMSO (maximum concentration $\leq 1 \%$ ), diluted with RPMI-1640, to final concentrations of $250-3.90 \mu \mathrm{g} / \mathrm{mL}$. An inoculum suspension $(100 \mu \mathrm{L}$ ) was added to each well (final volume in the well $=200 \mu \mathrm{L}$ ). A growth control well (GCW) (containing medium, inoculum, and the same amount of DMSO used in a CTW, but compound-free) and a sterility control well (SCW) (sample, medium, and sterile water instead of inoculum) were included for each fungus tested. Microtiter trays were incubated in a moist, dark chamber at $30{ }^{\circ} \mathrm{C}$ for $48 \mathrm{~h}$ for both yeasts. Microplates were read in a Versa Max microplate reader (Molecular Devices, Sunnyvale, CA, USA). Amphotericin B was used as positive control. Tests were performed in triplicate. Reduction of growth for each compound concentration was calculated as follows: $\%$ of inhibition $=100-\left(\mathrm{OD}{ }_{405} \mathrm{CTW}-\mathrm{OD}_{405} \mathrm{SCW}\right) /\left(\mathrm{OD}_{405} \mathrm{GCW}-\mathrm{OD}_{405} \mathrm{SCW}\right)$.

\subsection{Antituberculosis and Antibacterial Activity}

The agar dilution spot culture growth inhibition (SPOTi) assay [34,35] was performed to evaluate the minimum inhibitory concentration (MIC) values of the synthetic hybrids against the laboratory strain M. tuberculosis H37Rv in a biosafety level 3 laboratory of the National Health Institute in Bogota. A stock solution of the hybrids was prepared in DMSO at a concentration of $200 \mathrm{mg} / \mathrm{mL}$. Dilutions of the compounds were prepared in DMSO in 24 well plates, $2 \mathrm{~mL}$ of each dilution was dispensed in each well at 200, 100, 50, 20, and $10 \mathrm{mg} / \mathrm{mL}$. The final volume was $2 \mathrm{~mL}$ of molten Middlebrook 7H10 medium (HiMedia, Mumbai, India) supplemented with $0.5 \%$ glycerol and 10\% oleic acid, albumin, dextrose, and catalase (OADC, BD, USA) were added to the wells. An inoculum having a cell density of $10^{6} \mathrm{CFU} / \mathrm{mL}$ was prepared from a 2-week culture of M. tuberculosis H37Rv (ATCC 27294) grown in Löwenstein-Jensen medium slants at $37^{\circ} \mathrm{C}$. Two microliters of the diluted inoculum were dispensed in the middle of the agar from each well, and the plates were incubated for $2-3$ weeks at $37^{\circ} \mathrm{C}$. Isoniazid was included as a positive control at 10,1,0.1,0.05, and $0.01 \mu \mathrm{g} / \mathrm{mL}$ concentrations. After the incubation period, the plates were observed, and the MIC was determined as the minimum concentration on which growth was not observed. The experiment was repeated on a different day observing exactly 
the same results. The SPOTi agar dilution method was also employed for MIC determination against M. bovis BCG. The cells were passaged first in Middlebrook $7 \mathrm{H} 9$ and then spotted into Middlebrook 7H10 medium with supplement albumin, $0.5 \%$ glycerol, dextrose, and sodium chloride $(\mathrm{NaCl})$. The plates were incubated for 1 week at $37^{\circ} \mathrm{C}$. The concentrations tested were 200, 100, 50, 20 and $10 \mu \mathrm{g} / \mathrm{mL}$ and isoniazid was used as a positive control.

The evaluation of the hybrids against a panel of two Gram-negative microorganisms E. coli (see Table S1 in Supplementary Materials) and K. pneumoniae (see Table S2 in Supplementary Materials), and the Gram-positive bacteria S. aureus (see Table S3 in Supplementary Materials), with a varied pattern of drug-susceptibility was performed on LB broth by two-fold serial dilution with a maximum concentration of the synthetic hybrids at 200, 100, 50, 20, and $10 \mu \mathrm{g} / \mathrm{mL}$. Growth was determined by optical density measurements at $640 \mathrm{~nm}$ every $120 \mathrm{~min}$ for $36 \mathrm{~h}$. Chloramphenicol was used as a positive control, and the experiments were performed in duplicate.

\subsection{Cytotoxicity on VERO Cell Line}

The VERO cell line (ATCC ${ }^{\circledR}$ CCL-81 ${ }^{\mathrm{TM}}$ ) was cultured in Dulbecco Modified Eagle Medium (DMEM) supplemented with $10 \%$ bovine fetal serum (FBS) and 1\% streptomycin-penicillin and passaged twice before the assay in $21 \mathrm{~cm}^{2}$ cell culture Petri dishes at $37{ }^{\circ} \mathrm{C}$ in $5 \% \mathrm{CO}_{2}$ incubator and $100 \%$ humidity. The cells were then cultured in 96 well plates for $24 \mathrm{~h}$ before the assay to a cell density of 90.000 cells per well. A $10 \mathrm{mg} / \mathrm{mL}$ hybrid stock solution was prepared in DMSO, following 2-fold serial dilution until $0.01 \mathrm{mg} / \mathrm{mL}$. Finally, $5 \mu \mathrm{L}$ were transferred to each plate containing the VERO cells and incubated for $48 \mathrm{~h}$. Hydrogen peroxide was used as a positive control and DMSO as a negative control under the same dilution conditions. After $24 \mathrm{~h}$ of incubation, culture media was changed for $100 \mu \mathrm{L}$ of DMEM media without FBS freshly prepared with MTT solution at $5 \mathrm{mg} / \mathrm{mL}$, and the plates were further incubated for $2 \mathrm{~h}$. The media was then removed, and $100 \mu \mathrm{L}$ of DMSO was added to each well. After 30 min incubation, the absorbance was read at $540 \mathrm{~nm}$ on a microplate reader (FLUOstar Omega) [36]. The experiment was performed in duplicate on different days with different cell cultures and different stock of the hybrids. The $\mathrm{IC}_{50}$ values were determined by interpolation from the mean absorbance data of $100 \%$ viability (negative control) and $0 \%$ viability (positive control).

\section{Conclusions}

In summary, we report the antimicrobial activity of eight quinoline-based hydroxyimidazolium hybrids $\mathbf{7 a}-\mathbf{h}$ against panels of fungal and bacterial pathogens, including mycobacteria. Hybrid compounds $7 \mathbf{c}-\mathbf{d}$ showed the highest antifungal activity against $C$. with MIC values of $15.6 \mu \mathrm{g} / \mathrm{mL}$ each one. Furthermore, all hybrids showed promising antibacterial activity, although, compound $7 \mathbf{b}$ presented the strongest activity against S. aureus and M. tuberculosis H37Rv with MIC values of $2 \mu \mathrm{g} / \mathrm{mL}$ $(5 \mu \mathrm{M})$ and $10 \mu \mathrm{g} / \mathrm{mL}(24 \mu \mathrm{M})$, respectively.

Supplementary Materials: The following are available online at http://www.mdpi.com/2079-6382/8/4/239/s1, Table S1. Percentages of inhibition of Escherichia coli by hybrids $7 \mathbf{a}-\mathbf{h}$, Table S2. Percentages of inhibition of Klebsiella pneumoniae by hybrids $7 \mathbf{a}-\mathbf{h}$, Table S3. Percentages of inhibition of Staphylococcus aureus by hybrids $7 \mathbf{a}-\mathbf{h}$. Figure S1. Copies of ${ }^{1} \mathrm{H}$ NMR spectra for compounds $7 \mathbf{a}-\mathbf{h}$.

Author Contributions: D.I., B.I., J.Q., and R.A. designed the target compounds and performed the synthetic experiments; S.Z. and L.S. planned and performed the antifungal assays and drew the graphics; D.I., O.V., A.B., E.M., J.G., and G.P. planned and performed the antibacterial assays and drew the graphics; all authors contributed in writing the paper.

Funding: This research received no external funding.

Acknowledgments: The authors gratefully acknowledge financial support from COLCIENCIAS, Universidad del Valle, Universidad del Norte. L.S. and S.Z. acknowledge Agencia Nacional de Promoción Científica y Tecnológica (ANPCyT), PICT2016-1833, and the National University of Rosario, Argentina (UNR) for funds. L.S. is a member of the Consejo Nacional de Investigaciones Científicas y Técnicas (CONICET) researcher career.

Conflicts of Interest: The authors declare no conflict of interest. 


\section{References}

1. Andersson, D.I.; Diarmaid, H. Antibiotic resistance and its cost: is it possible to reverse resistance? Nat. Microbiol. Rev. 2010, 8, 260-269. [CrossRef] [PubMed]

2. Geddes-McAlister, J.; Shapiro, R.S. New pathogens, new tricks: Emerging, drug-resistant fungal pathogens and future prospects for antifungal therapeutics. Ann. N. Y. Acad. Sci. 2019, 1435, 57-78. [CrossRef] [PubMed]

3. Bhagat, K.; Bhagat, J.; Gupta, M.K.; Singh, J.V.; Gulati, H.K.; Singh, A.; Kaur, K.; Kaur, G.; Sharma, S.; Rana, A.; et al. Design, synthesis, antimicrobial evaluation, and molecular modeling studies of novel indolinedione-coumarin molecular hybrids. ACS Omega 2019, 4, 8720-8730. [CrossRef] [PubMed]

4. Desai, N.; Trivedi, A.; Pandit, U.; Dodiya, A.; Kameswara Rao, V.; Desai, P. Hybrid bioactive heterocycles as potential antimicrobial agents: a review. Mini Rev. Med. Chem. 2016, 16, 1500-1526. [CrossRef] [PubMed]

5. Zhang, J.; Wang, S.; Ba, Y.; Xu, Z. 1,2,4-Triazole-quinoline/quinolone hybrids as potential anti-bacterial agents. Eur. J. Med. Chem. 2019, 174, 1-8. [CrossRef]

6. Sharma, A.; Gupta, V.K.; Pathania, R. Efflux pump inhibitors for bacterial pathogens: From bench to bedside. Indian J. Med. Res. 2019, 149, 129-145.

7. World Health Organization. Guidelines for the Treatment of Malaria; World Health Organization: Geneva, Switzerland, 2015; ISBN 92-4-154912-2.

8. Bisacchi, G.S. Origins of the quinolone class of antibacterials: An expanded "discovery story". J. Med. Chem. 2015, 58, 4874-4882. [CrossRef]

9. Hooper, D.C.; Wolfson, J.S. Fluoroquinolone antimicrobial agents. N. Engl. J. Med. 1991, 324, 384-394.

10. Koul, A.; Vranckx, L.; Dhar, N.; Göhlmann, H.W.H.; Özdemir, E.; Neefs, J.-M.; Schulz, M.; Lu, P.; Mørtz, E.; McKinney, J.D.; et al. Delayed bactericidal response of Mycobacterium tuberculosis to bedaquiline involves remodelling of bacterial metabolism. Nat. Commun. 2014, 5, 1-10. [CrossRef]

11. Datta, S.; He, G.; Tomilov, A.; Sahdeo, S.; Denison, M.S.; Cortopassi, G. In vitro evaluation of mitochondrial function and estrogen signaling in cell lines exposed to the antiseptic cetylpyridinium chloride. Environ. Health Perspect. 2017, 125, 087015. [CrossRef]

12. Khajavi, R.; Sattari, M.; Ashjaran, A. The antimicrobial effect of benzalkonium chloride on some pathogenic microbes observed on fibers of acrylic carpet. Pakistan J. Biol. Sci. 2007, 10, 598-601. [CrossRef] [PubMed]

13. Sawyer, P.R.; Brogden, R.N.; Pinder, R.M.; Speight, T.M.; Avery, G.S. Clotrimazole: A review of its antifungal activity and therapeutic efficacy. Drugs 1975, 9, 424-447. [CrossRef] [PubMed]

14. Cutsem, J.V. The antifungal activity of ketoconazole. Am. J. Med. 1983, 74, 9-15. [CrossRef]

15. Sawyer, P.R.; Brogden, R.N.; Pinder, R.M.; Speight, T.M.; Avery, G.S. Miconazole: A review of its antifungal activity and therapeutic efficacy. Drugs 1975, 9, 406-423. [CrossRef]

16. Cui, B.; Zheng, B.L.; He, K.; Zheng, Q.Y. Imidazole alkaloids from lepidium meyenii. J. Nat. Prod. 2003, 66, 1101-1103. [CrossRef]

17. Elshaarawy, R.F.; Janiak, C. Toward new classes of potent antibiotics: Synthesis and antimicrobial activity of novel metallosaldach-imidazolium salts. Eur. J. Med. Chem. 2014, 75, 31-42. [CrossRef]

18. Riduan, S.N.; Zhang, Y. Imidazolium salts and their polymeric materials for biological applications. Chem. Soc. Rev. 2013, 42, 9055-9070. [CrossRef]

19. Wang, D.; Richter, C.; Rühling, A.; Hüwel, S.; Glorius, F.; Galla, H.-J. Anti-tumor activity and cytotoxicity in vitro of novel 4, 5-dialkylimidazolium surfactants. Biochem. Biophys. Res. Commun. 2015, 467, 1033-1038. [CrossRef]

20. Laali, K.K.; Insuasty, D.; Abonia, R.; Insuasty, B.; Bunge, S.D. Novel quinoline-imidazolium adducts via the reaction of 2-oxoquinoline-3-carbaldehyde and quinoline-3-carbaldehydes with 1-butyl-3-methylimidazolium chloride [BMIM][Cl]. Tetrahedron Lett. 2014, 55, 4395-4399. [CrossRef]

21. Meth-Cohn, $\mathrm{O}$. The synthesis of pyridines, quinolines and other related systems by the Vilsmeier and the reverse Vilsmeier method. Heterocycles 1993, 35, 539-557. [CrossRef]

22. Clinical and Laboratory Standards Institute (CLSI). Document M27A3. In Reference Method For Broth Dilution Antifungal Susceptibility Testing of Yeasts; CLSI: Wayne, PA, USA, 2008; pp. 1-25.

23. Clinical and Laboratory Standards Institute (CLSI). Document M38A2. In Reference Method For Broth Dilution Antifungal Susceptibility Testing of Filamentous Fungi; CLSI: Wayne, PA, USA, 2008; pp. 1-35. 
24. Desai, N.C.; Rajpara, K.M.; Joshi, V.V.; Vaghani, H.V.; Satodiya, H.M. Synthesis, characterization and antimicrobial screening of hybrid molecules containing quinoline, pyrimidine and morpholine analogues. J. Chem. Sci. 2013, 125, 321-333. [CrossRef]

25. Desai, N.C.; Rajpara, K.M.; Joshi, V.V. Synthesis and characterization of some new quinoline based derivatives endowed with broad spectrum antimicrobial potency. Bioorg. Med. Chem. Lett. 2012, 22, 6871-6875. [CrossRef] [PubMed]

26. Mishra, A.; Batchu, H.; Srivastava, K.; Singh, P.; Shukla, P.K.; Batra, S. Synthesis and evaluation of new diaryl ether and quinoline hybrids as potential antiplasmodial and antimicrobial agents. Bioorg. Med. Chem. Lett. 2014, 24, 1719-1723. [CrossRef] [PubMed]

27. Nayak, N.; Ramprasad, J.; Dalimba, U. Synthesis and antitubercular and antibacterial activity of some active fluorine containing quinoline-pyrazole hybrid derivatives. J. Fluor. Chem. 2016, 183, 59-68. [CrossRef]

28. Keri, R.S.; Patil, S.A. Quinoline: A promising antitubercular target. Biomed. Pharmacother. 2014, 68, 1161-1175. [CrossRef] [PubMed]

29. Singh, K.; Kaur, H.; Smith, P.; de Kock, C.; Chibale, K.; Balzarini, J. Quinoline-Pyrimidine Hybrids: Synthesis, Antiplasmodial Activity, SAR, and Mode of Action Studies. J. Med. Chem. 2014, 57, 435-448. [CrossRef]

30. Guantai, E.M.; Ncokazi, K.; Egan, T.J.; Gut, J.; Rosenthal, P.J.; Bhampidipati, R.; Kopinathan, A.; Smith, P.J.; Chibale, K. Enone- and Chalcone-Chloroquinoline Hybrid Analogues: In Silico Guided Design, Synthesis, Antiplasmodial Activity, in Vitro Metabolism, and Mechanistic Studies. J. Med. Chem. 2011, 54, 3637-3649. [CrossRef]

31. Sashidhara, K.V.; Avula, S.R.; Mishra, V.; Palnati, G.R.; Singh, L.R.; Singh, N.; Chhonker, Y.S.; Swami, P.; Bhatta, R.S.; Palit, G. Identification of quinoline-chalcone hybrids as potential antiulcer agents. Eur. J. Med. Chem. 2015, 89, 638-653. [CrossRef]

32. Mantoani, S.; Chierrito, T.; Vilela, A.; Cardoso, C.; Martínez, A.; Carvalho, I. Novel Triazole-Quinoline Derivatives as Selective Dual Binding Site Acetylcholinesterase Inhibitors. Molecules 2016, 21, 193. [CrossRef]

33. Camps, P.; Formosa, X.; Galdeano, C.; Muñoz-Torrero, D.; Ramírez, L.; Gómez, E.; Isambert, N.; Lavilla, R.; Badia, A.; Clos, M.V. Pyrano[3,2-c]quinoline-6-Chlorotacrine Hybrids as a Novel Family of Acetylcholinesterase- and $\beta$-Amyloid-Directed Anti-Alzheimer Compounds. J. Med. Chem. 2009, 52, 5365-5379. [CrossRef]

34. Guzman, J.D.; Gupta, A.; Evangelopoulos, D.; Basavannacharya, C.; Pabon, L.C.; Plazas, E.A.; Muñoz, D.R.; Delgado, W.A.; Cuca, L.E.; Ribon, W. Anti-tubercular screening of natural products from Colombian plants: 3-methoxynordomesticine, an inhibitor of MurE ligase of Mycobacterium tuberculosis. J. Antimicrob. Chemother. 2010, 65, 2101-2107. [CrossRef] [PubMed]

35. Evangelopoulos, D.; Bhakta, S. Rapid Methods for Testing Inhibitors of Mycobacterial Growth. In Antibiotic Resistance Protocols, 2nd ed.; Gillespie, S.H., McHugh, T.D., Eds.; Methods in Molecular Biology; Humana Press: Totowa, NJ, USA, 2010; pp. 193-201. ISBN 978-1-60327-279-7.

36. Van Meerloo, J.; Kaspers, G.J.L.; Cloos, J. Cell Sensitivity Assays: The MTT Assay. In Cancer Cell Culture: Methods and Protocols; Cree, I.A., Ed.; Methods in Molecular Biology; Humana Press: Totowa, NJ, USA, 2011; pp. 237-245. ISBN 978-1-61779-080-5.

(C) 2019 by the authors. Licensee MDPI, Basel, Switzerland. This article is an open access article distributed under the terms and conditions of the Creative Commons Attribution (CC BY) license (http://creativecommons.org/licenses/by/4.0/). 